NASA Technical Memorandum 105944

\title{
Improved Techniques for Thermomechanical Testing in Support of Deformation Modeling
}

Michael G. Castelli

Sverdrup Technology, Inc.

Lewis Research Center Group

Brook Park, Ohio

and

John R. Ellis

National Aeronautics and Space Administration

Lewis Research Center

Cleveland, Ohio

November 1992

\section{N/SA}




\title{
IMPROVED TECHNIQUES FOR THERMOMECHANICAL TESTING IN SUPPORT OF DEFORMATION MODELING
}

\author{
Michael G. Castelli ${ }^{1}$ and John R. Ellis ${ }^{2}$
}

\begin{abstract}
The feasibility of generating precise thermomechanical deformation data to support constitutive model development was investigated. Here, the requirement is for experimental data that is free from anomalies caused by less than ideal equipment and procedures. A series of exploratory tests conducted on Hastelloy X showed that generally accepted techniques for strain controlled tests were lacking in at least three areas. Specifically, problems were encountered with specimen stability, thermal strain compensation and temperature/mechanical strain phasing. The present study was undertaken to identify the source of these difficulties and to develop improved thermomechanical testing techniques to correct them. These goals were achieved by developing improved procedures for measuring and controlling thermal gradients and by designing a specimen specifically for thermomechanical testing. In addition, innovative control strategies were developed to correctly proportion and phase the thermal and mechanical components of strain. Subsequently, the improved techniques were used to generate deformation data for Hastelloy $\mathrm{X}$ over the temperature range, 200 to $1000^{\circ} \mathrm{C}$.
\end{abstract}

\section{Introduction}

Overview

The majority of structural components used in high temperature applications experience some form of thermomechanical loading during service. In order to predict performance under such loadings, it is essential that precise thermomechanical tests be conducted on candidate materials. In particular, if thermomechanical testing is performed in support of constitutive model development, the data must be free of anomalies introduced by less than ideal test equipment and control techniques. To this end, recent advances in digital control systems, instrumentation, and mechanical testing equipment have eliminated many of the difficulties encountered in earlier studies. However, maintaining closely controlled conditions during thermomechanical loading remains a relatively complex task, requiring detailed examination. It is also worthy to note that to date, a standard recommended practice for conducting thermomechanical deformation and/or fatigue testing does not exist.

A state-of-the-art testing facility has been established at NASA Lewis in support of high temperature deformation and fatigue testing of advanced materials. A number of exploratory tests were conducted to investigate the feasibility of generating precise

\footnotetext{
'Structures Research Engineer, Sverdrup Technology Inc., LeRC Group, Brook Park, Ohio 44142

${ }^{2}$ Chief of Fatigue and Fracture Branch, NASA Lewis Research Center, Cleveland, Ohio 44135
} 
thermomechanical deformation (TMD) data to support constitutive model development. The testing involved controlled time phasing between the temperature and mechanical strain components under uniaxial strain control; these relationships are shown in Fig. 1. The inphase and out-of-phase relationships described in Fig. 1 represent bounding or "extreme" relationships between the control variables and are therefore typically selected for TMD testing. A triangular waveform was used to control both temperature and mechanical strain as data generated at a constant loading rate is preferred in constitutive model development. Thermomechanical testing under uniaxial strain control gives rise to complex control conditions because of the first order affect of thermal strain on the control variable [1-4]. Because of this added complexity, the techniques detailed in this paper will pertain directly to thermomechanical, uniaxial strain controlled testing with triangular command waveforms. However, the techniques are equally applicable to the less complicated mode of load control. Also note that although this paper details deformation testing, the control techniques presented are also applicable to fatigue testing. The exception here may be the technique used for temperature measurement, i.e. the use of intrinsic thermocouples, as this technique mares the specimen surface, potentially enhancing crack initiation at these locations.

Initial exploratory tests under strain-controlled thermomechanical conditions identified three general areas which were found to be lacking, namely, specimen stability, thermal strain compensation, and temperature-mechanical strain phasing. These three areas were investigated in detail and experimental techniques and procedures were developed to improve the accuracy of each.

\section{Problem Areas/Issues}

The first problem area identified pertains to specimen stability during thermomechanical testing. For Hastelloy $\mathrm{X}^{3}$, out-of-phase loadings conducted at temperatures greater than $600^{\circ} \mathrm{C}$ were found to introduce a cyclic specimen instability referred to as barreling. This behavior has been noted in several materials under a variety of loading conditions [4-11]. Barreling is a cycle-by-cycle ratchetting phenomenon promoting material flow and localized straining; on a cylindrical specimen, this behavior is evidenced as circumferential bulging. Fig. 2 shows a test specimen before and after barreling. In severe cases the barreling is visually detectable very early in cyclic life $\left(\mathrm{N}<0.2 \mathrm{~N}_{\mathrm{f}}\right)$. The test specimen eventually becomes so severely distorted that initial engineering values of stress and strain lose all significance, complicating interpretation of the data. For Hastelloy X, the barreling did not occur under either isothermal or in-phase loading conditions.

Although this behavior has been noted on several different materials during high temperature deformation, investigators have only speculated as to its cause [4-11] and how it relates to the specific test conditions. The barreling has been attributed in part to several sources including inelastic strain magnitude, strain rate, specimen geometry, and mean stress. However, there has been little or no success at eliminating this problem under conditions where it has been found to occur.

The second area identified as requiring improvement was that of thermal strain compensation during a strain-controlled thermomechanical test. If a fixed mechanical strain range is required, an accurate assessment of and compensation for the thermal strain

\footnotetext{
${ }^{3}$ Hastelloy $X$ is a trademark of Haynes International, Inc., Kokomo, IN.
} 
component must be maintained at all times during the TMD cycle. Two simplified approaches can be taken. The first approach is to assume that the thermal strain range can be accurately subdivided into equal strain increments corresponding to equal time increments throughout the cycle. Real-time thermal strain compensation is then accomplished by adding (or subtracting) this constant increment to the desired mechanical strain increment (also constant). This approach can lead to significant errors if the specimen's thermal strain response is not linear with respect to the temperature range, and also if the thermal strains are not consistently linear with respect to time, a condition which is typical during temperature reversals. The second approach is to assume that the thermal strains can be accurately represented by a single thermal cycle recorded prior to the test. This pre-recorded thermal strain versus time history is subsequently accessed (based on cycle time) to obtain the "realtime" thermal strain component. This approach will promote control errors if small temperature variations are experienced within a cycle or from one cycle to the next. The prerecorded thermal strains remain fixed in time, while the actual thermal strains are likely to fluctuate.

The third area where problems most often arise during thermomechanical testing is that of command variable phasing. This is a problem because the time lag experienced between the command and actual specimen response is different when comparing temperature to mechanical strain (This is also a problem in load-controlled tests.). With state-of-the-art equipment, the response lag value for the mechanical component of loading is essentially zero. However, the response lag value for temperature can be quite large, particularly when a command reversal is issued. Simplified approaches, including simultaneous commands or a mathematical coupling between the mechanical strain command and the temperature response, will usually result in distorted hysteresis loops, such as those shown in Fig 3. These distortions will be evident, both in the stress - total strain space (Fig. 3a), and after postprocessing in the stress - mechanical strain space (Fig. 3b). Such distortions are unacceptable in data intended to support constitutive model development.

\section{Experimental Details}

Equipment

The load-train of the closed-loop, servo-hydraulic test system used for this study is shown in Fig. 4. Specimens are installed in water-cooled hydraulic grips which incorporate collets for gripping a variety of specimen end geometries. During the TMD cycle, the grips serve as the primary mechanism for specimen cooling. The maximum temperature rate is generally governed by the cooling portion of the cycle, particularly when relatively "low" temperatures are involved in the TMD cycle. Forced air can be used as a means of specimen cooling, however, even if the air is diffused, highly localized cooling (and thus, localized heating) is likely to occur where the air streams impinge the surface of the specimen. For this reason, forced air cooling was not used in this study.

A high temperature, water-cooled extensometer is used to measure axial strains. An axial gage length of $12.7 \mathrm{~mm}$ is selected over a length of $25.4 \mathrm{~mm}$ because it is easier to control thermal gradients over the shorter test section. Direct induction is used for specimen heating. This method is convenient for rapid heating and temperature cycling, and allows relatively free access to the specimen's surface to accommodate the extensometer's probes. Power is provided by a radio frequency (RF) induction heater integrated with a closed loop temperature controller. Type $\mathrm{K}$ thermocouple wires are spot-welded onto the specimen's 
surface (i.e. intrinsic thermocouples) to monitor the temperature at several locations.

Typically, induction work coils are constructed with a continuous single segment design, not allowing independent adjustments of the individual windings. Hence, coil adjustments, directly interpreted as temperature changes along the specimen, cannot be pursued in a systematic manner. In contrast, the work coils and support fixture [12] used here, shown in Fig. 5, consists of three independent coil segments. Each segment is individually adjustable in vertical and radial directions, allowing a systematic approach to temperature modification at localized positions along the specimen.

A minicomputer was used for test control. Control software was written to implement the improved thermomechanical testing techniques developed in this study and manage the data acquisition. The use of RF induction heating will often introduce a significant amount of electrical noise which is highly visible in the digital data. An averaging scheme was implemented in the data acquisition routine to sample the input signals several times and compute an average before writing to the disk. This scheme was successful in the presence of unbiased electrical noise.

Specimen Design

Initial TMD tests were conducted on a specimen geometry originally designed for isothermal, low cycle fatigue (LCF) testing. This design is shown in Figs. 2 \& 6a. Although specimen geometry was not found to directly affect the material instability, an improved design was established which assisted in reducing the dynamic temperature gradients, and thus, indirectly aided in reducing material barreling. This specimen geometry is shown in Fig. 6b. The improved design is a smooth shank, thin walled tube with an extended parallel working section. In comparison to the solid cross-section specimen design (Fig. 6a), the tubular construction allows for higher heating and cooling rates while maintaining a high degree of waveform control. Also, the tubular geometry inherently lowers the radial temperature gradients present during thermal cycling. Another advantage of this design over the original solid specimen is the extended central parallel section. This feature provides sufficient length to fully accommodate the induction heater work coils, thereby simplifying the relationship between coil adjustment and associated temperature change.

\section{Improved Techniques}

Dynamic Thermal Gradients/Specimen Stability

The specimen barreling noted in the present work often appeared in the form of two bulges occurring above and below the midpoint of the specimen's gage section; see Fig. 2 . After closely monitoring the temperature gradients over the length of the specimen during the TMD cycle (i.e. the dynamic temperature gradients), it was determined that the bulge locations were associated with hot spots (hotter by approximately $10^{\circ} \mathrm{C}$ ) existing at the maximum temperature of the cycle. The correspondence between barreling and the location of a hot spot during temperature cycling was verified by conducting a test with an imposed dynamic hot spot at the mid-gage position. As suspected, the location of the barreling was mid-gage, coincidental with the location of the hot spot during cycling. This clearly identified dynamic thermal gradients as a primary source of the material barreling. Further testing revealed that gradients of seemingly insignificant severity (e.g. $\pm 5^{\circ} \mathrm{C} /$ gage) were instrumental in promoting barreling under out-of-phase loadings above $600^{\circ} \mathrm{C}$. Thus, to 
minimize the specimen barreling, effort was placed on refining the techniques used to measure and control dynamic thermal gradients over the gage section. Note that the procedures and techniques discussed below will be influenced to some degree by specific test material and equipment.

Clearly, close control of thermal gradients requires precise temperature measurement over the specimen's gage section. Measurements indicated by a thermocouple reflect the temperature at a highly localized point (i.e. the exact point of physical contact). Experience has shown that direct induction heating can create highly localized "hot" spots. Thus, it is important to place the thermocouples sufficiently close, so as to insure these "hot" spots are detected. After examining several possible configurations, a satisfactory arrangement was established and is shown in Fig. 7. An axial separation of approximately $6 \mathrm{~mm}$ provides adequate resolution for temperature monitoring. This eleven-thermocouple system includes two sets of five on opposite sides of the specimen $\left(180^{\circ}\right.$ circumferential separation), and one located on the back-side of the specimen (opposite the extensometer probes) to function as the feedback sensor for closed-loop temperature control. The redundant set of five allows verification of the temperature in a circumferential sense as well as a check on the gradients present in the axial direction.

The next step is obtaining a "proper" static temperature profile. Initial testing had revealed that the dynamic temperature gradients were not equal to the static gradients present prior to temperature cycling. Depending upon temperature rate, a static gradient of $\pm 3^{\circ} \mathrm{C}$ could increase to a dynamic gradient of $\pm 15^{\circ} \mathrm{C}$ over the $12.7 \mathrm{~mm}$ gage section. More specifically, the gage length extremes (positions marked "upper" and "lower" on Fig. 7) experienced temperatures approximately $15^{\circ} \mathrm{C}$ hotter at the maximum cycle temperature, and approximately $15^{\circ} \mathrm{C}$ cooler at the minimum cycle temperature, than that found at the mid-section of the gage length.

By way of explanation, recall the configuration of the direct induction coils in Fig 5. Heating is induced by two major and one minor coil winding. Gaps in the windings are necessary to accommodate the extensometer probes. During an increasing temperature ramp, the locations within the major coils will tend to heat faster than the location encircled by the minor (center) coil. This condition can possibly be avoided through the use of multi-zone control. However, the control complications introduced by such a system under TMD conditions may out-weigh the advantages, as each of the zones will require individual mechanical strain/temperature phasing considerations. Specimen cooling is facilitated by the water-cooled grips. This arrangement will inevitably impose a cold-hot-cold (top-center-bottom) axial thermal gradient along the full length of the specimen. During a decreasing temperature ramp, a variable cooling rate along the length of the specimen will be realized, as the ends will cool more rapidly than the mid-section. Thus, both heating rates and cooling rates are higher at the gage length extremes, compared to the specimen mid-section.

In addition to these symmetric anomalies, testing in air allows thermal convection currents to play a role in dynamic temperature gradients. A point located within the lower length of the specimen typically requires more energy than its counterpart within the upper length when a uniform temperature is desired. This effect can be countered under static (isothermal) conditions by proper coil adjustments. However, dynamic (thermomechanical) conditions lead to increased heating rates within the upper length during the heating portion of the cycle, and increased cooling rates within the lower length during the cooling portion of 
the cycle.

Given these constraints, it is impossible to cycle temperature without inducing gradients in the gage section. At best, it is possible to eliminate gradients at a specific temperature in the cycle. Three obvious points are considered: 1) average-cycle temperature, 2) maximum cycle temperature and 3) minimum cycle temperature, as schematically represented in Fig. 8. Given that the material barreling increases with increasing temperature, and is associated with the "hot" spots in the gradient, a dynamic temperature profile minimizing the gradients at the maximum cyclic temperature is chosen (i.e. Fig. 8b). With this specific dynamic condition requirement, a corresponding static condition with initial imposed gradients can be established. This technique allows the hot-end dynamic gradients to be reduced to approximately $\pm 2{ }^{\circ} \mathrm{C}$ over the gage section. Note that by choosing this condition, the cold-end gradients increased. Also note that multi-zone temperature control can potentially minimize this problem.

Another related issue concerns the uniformity of the temperature rate. Several axial locations are found to experience a fluctuating temperature rate after reversal. The closed loop temperature control system uses a thermocouple as the feedback sensor, hereafter called the controlling thermocouple (CTC). Strictly speaking, for the case of single zone control, only the CTC temperature rate is controlled; the temperature rates at all other points along the specimen may deviate from the controlled location. Typically, the CTC is placed at a central position within the gage section. Shown in Fig. 9 is the dynamic thermal profile of a specimen cycled from $600-800^{\circ} \mathrm{C}$ with the CTC in the "center" position. Here, waveform distortions are revealed at both the "upper" and "lower" gage locations after temperature reversals. This effect can be understood by recalling that locations away from the center of the gage section have a higher heating and cooling rate, and hence, these positions respond more quickly to heater adjustments. The solution to this problem is to place the CTC at a "quick" response position. Shown in Fig. 10 is a comparable thermal cycle with the CTC at the "top" position (as defined in Fig. 7). Obvious improvements are visible when controlling from this position. The CTC is now more responsive (relatively) to heater output changes, thereby eliminating conditions of under and over-heating at other locations during reversals. The variation in thermal response with respect to position is now perceived as a slight lingering of the "center" position during reversals, as linearity is no longer forced at this position. Utilization of this "top" CTC position reduces dynamic thermal gradients and assists in maintaining linear temperature waveforms within the gage section.

The rate of thermal cycling was found to have the greatest influence on all other control parameters; as temperature rate increased all other aspects became more difficult to control. Rates from $25-200^{\circ} \mathrm{C} / \mathrm{min}$ were investigated while monitoring dynamic gradients, temperature rate constancy, and thermal strain compensation. At the higher rates, dynamic temperature gradients became unacceptably high (e.g. $\pm 30^{\circ} \mathrm{C}$ over the gage section) and accurate thermal strain compensation was not possible. To maintain the desired degree of control, a maximum temperature rate of $50^{\circ} \mathrm{C} / \mathrm{min}$. was used.

Thermal Strain Compensation

A strain-controlled environment is preferred in experiments supporting constitutive equation development. However, under TMD, difficulties arises in the test control parameters because of the thermal strain's contribution to the total strain. If a fixed mechanical strain range is required, accurate thermal strain compensation is necessary. After evaluating several 
techniques, an improved methodology was developed and implemented.

The preferred approach is to relate thermal strain to real-time measurement of specimen temperature. This method relies upon the assumption that a function is capable of representing the thermal strains using an effective coefficient of thermal expansion (ECTE) which correlates the gage section strains to a single temperature measurement. If the temperature range is relatively small, a linear function will perform adequately. However, this is not usually the case with large temperature ranges. Here the non-linear relationship between temperature and strain can be well approximated by a piece-wise linear function. Higher order polynomials can also be employed. However, these functions are not "well behaved" outside the direct input domain and the added complexity is often not justified.

The first step is to determine the physical location of the temperature feedback. After evaluating several axial locations, as well as cases where a temperature feedback is generated by averaging temperatures from several locations, the "top" position (Fig. 7) is selected as performing best, particularly during temperature reversals. This location's comparatively quick response characteristics make it most suitable for use in a linear thermal strain equation;

$$
\varepsilon^{\text {th }}=\alpha^{*} T+C
$$

Here, $\alpha^{*}$ is the ECTE, $\mathrm{C}$ is a constant, and T is the real-time specimen temperature at a "top" positioned thermocouple. The specimen is thermally cycled with load held zero to obtain the value for $\alpha^{*}$. To insure the accuracy of $\alpha^{*}$, the specimen is again thermally cycled, but this time in strain control, where the thermal strain equation is commanding the "compensating" strains.

Shown in Fig. 11 are the possible results from this cycle, assuming a single linear relationship is valid. Figs. $11 \mathrm{a}$ and $11 \mathrm{~b}$ represent cases where $\alpha^{*}$ is greater than and less than, respectively, the optimal value $\left(\alpha_{0}\right)$. Fig. 11c depicts a condition where $\alpha^{*}$ is accurate during the linear temperature ramp, however, became an invalid relationship during reversals. This condition exists if the temperature rate is too fast and well controlled reversals are not maintained. If the equation is working properly, the specimen is cycled in strain control without inducing a notable stress in the specimen (Fig. 11d). Conditions are considered to be well controlled if the induced stress is maintained to within $1 \%$ of the maximum stress anticipated in the TMD test. During the test, the total strain command is calculated by summing two independent functions, thermal strain and mechanical strain. This flexible technique is accurate and capable of representing cycle-to-cycle variations in actual specimen temperature.

\section{Temperature/Mechanical Strain Phasing}

Phasing problems arise in thermomechanical loadings because of command/response $(\mathrm{C} / \mathrm{R})$ time differences between mechanical strain and temperature. The $\mathrm{C} / \mathrm{R}$ time is defined as the real time elapsed between issuing a command and obtaining the response on the test specimen. Mechanical loading frames are capable of rapid real-time response, allowing the $\mathrm{C} / \mathrm{R}$ time of the mechanical strain component to be insignificant. In contrast, the $\mathrm{C} / \mathrm{R}$ time for temperature is comparatively large, particularly during command reversals.

The temperature/mechanical strain phasing technique is designed with an emphasis on maintaining a constant mechanical strain rate. The mechanical strain is calculated by a single, time-based, temperature independent function, ensuring a constant rate throughout the complete cycle. In contrast, two temperature command functions are utilized. The first, 
referred to as a master/slave command, is dependent on, and slaved to, the mechanical strain function. The second, referred to as a decoupled command, is calculated independent of the mechanical strain function. The sequence in which the temperature commands are issued is shown in Fig. 12.

During portions of the cycle which are not in the vicinity of a command reversal, a master/slave relationship is used to calculate the temperature command. At a pre-determined point prior to a command reversal, the temperature command is decoupled from the mechanical strain function and forced to reverse prematurely (Fig. 12, point a). This point is determined by thermal cycle trials (under zero load) prior to the TMD test and is selected such that the actual temperature response reversal occurs simultaneously with the mechanical strain command reversal (Fig. 12, point b). Representative time values between points a and $\mathrm{b}$ are 3 to 8 seconds depending upon specific system configurations, temperature and temperature rate. Note that the value of this interval at the "cold" end of the cycle will likely be different from that established at the "hot" end of the cycle, with the "cold" end value typically greater. As a result of the premature reversal, the temperature command waveform is pushed "ahead" of the mechanical strain waveform. This offset prevents the mechanical strain and temperature commands from being immediately re-coupled into the previous master/slave relationship after reversal. Therefore, a slightly reduced temperature increment ( $\approx 95 \%$ of the slaved command increment) is used after the response reversal (Fig. 12 point b). At the point of intersection with the master/slave command waveform (Fig. 12, point c), the temperature command is re-coupled, and once again calculated by the master/slave relationship. By making use of this technique, reasonably precise phasing can be maintained during reversals without affecting the constant mechanical strain rate, and accurate hysteresis loops (free of distortions) can be obtained.

Strictly speaking, during the de-coupled portion of the cycle after point b (Fig. 12), the temperature and mechanical strain response are out of proper phasing. However, this slight phase shift occurs during the initial portion of the elastic unload and does not introduce abnormal distortions in the deformation response. Also, given the real-time calculations for thermal strain compensation (discussed above), no mechanical strain errors are introduced. This methodology is felt to be the best compromise for maximizing accuracy and control.

\section{Discussion}

The improved thermomechanical testing techniques and procedures described above have been implemented into a real-time test control code and integrated into a state-of-the-art high temperature mechanical testing system. A schematic flow diagram depicting the command and execution sequencing is shown in Fig 13. As shown, the two control signals, total strain $\left(\mathrm{e}_{2}\right)$ and temperature $\left(\mathrm{T}_{2}\right)$, are digitally generated by the microprocessor and converted to analog signals. The thermal component of the total strain is a function of the real-time specimen temperature $\left(\mathrm{T}_{1}\right)$ and thus requires an incoming signal for control purposes. All remaining control functions are generated as explicit or implicit functions in real-time. Additional analog signals (i.e. total strain and load) are sampled and recorded.

Given a suitable test system and the control software described above, the sequence for set up and test initiation is as follows. First, temperature ranges and rates are established. Without forced air cooling of the specimen, the cooling portion of the cycle and the desired minimum temperature will dictate the maximum temperature rate. However, from a control standpoint, it is often advantageous to use a temperature rate less than the maximum 
manageable rate, as typically, temperature gradients, phasing control, and thermal strain compensation all improve with decreasing temperature rate. After having established a temperature range and rate, the dynamic temperature gradients over the gage section should be adjusted to desired values. This will require thermal cycling the specimen (under zero load) prior to the TMD test. With all tuning and adjustments to the temperature cycle complete, the next step is to determine appropriate time values for the premature temperature command reversals. Again, this is accomplished by comparing the temperature commands to the actual temperature response during thermal cycling under zero load. The final step is to calculate an appropriate ECTE under load control and verify the accuracy of the thermal strain compensation function under strain control. This final step will indicate whether or not the various test parameters have been appropriately selected. If this verification does not produce satisfactory results, it will be necessary to adjust one or more of the test conditions (e.g. temperature rate) and determine revised test parameters.

Having established the improved techniques, a TMD condition associated with severe material barreling was re-visited. A $600-800^{\circ} \mathrm{C}$, out-of-phase test with $\varepsilon^{\mathrm{m}}= \pm 0.003 \mathrm{~m} / \mathrm{m}$ was conducted; this loading condition consistently promoted severe material barreling after approximately 300-500 cycles. The results of this experiment are shown in Fig. 14, along side an earlier test subjected to identical loading conditions. The specimen tested before implementing the refined techniques was discontinued at 500 cycles. The barreling was visible after only 300 cycles. The specimen tested using the improved techniques experienced over 1100 cycles at which time the test was terminated because of macroscopic cracking. The barreling within the gage section was effectively minimized. A small increase in diameter was experienced above the gage section where strict gradient control was not enforced. Since the cross section of the gage remained constant throughout the duration of the test, the deformation data obtained could be used with a high degree of confidence.

Although the material barreling was clearly associated with temperature gradients present during thermomechanical loading, it is likely that other factors contribute to this phenomenon. As this is a ratchetting/flow type process, the magnitude of inelastic strain will likely have an influence, as suggested by Coffin in Ref. 6. A series of $600-800^{\circ} \mathrm{C}$ out-ofphase tests were conducted with similar initial static gradients $\left( \pm 3^{\circ} \mathrm{C}\right)$ over the gage section. Each test was performed with a different mechanical strain range including 0 (thermal cycle only), $\pm 0.002, \pm 0.003$, and $\pm 0.004 \mathrm{~m} / \mathrm{m}$. The thermomechanical cycles were periodically interrupted under controlled conditions for careful outer diameter measurements. Results are shown in Fig. 15 where the diameter increase at the location of most pronounced barreling was reported. The tests reveal that the material barreling is highly influenced by degree of inelastic strain. As previously observed, the barreling was located at dynamic hot spots. It is worthy to note that the specimen did not barrel under "thermal cycle only" conditions, but rather, a small mechanical load was necessary to promote the behavior.

The improved techniques described herein resulted in the capability to perform well controlled, accurate, TMD experiments. These techniques were used to conduct a series of strain-controlled TMD tests on the nickel-base superalloy, Hastelloy $\mathrm{X}$, at temperatures from $200-1000^{\circ} \mathrm{C}$. A temperature range of $200^{\circ} \mathrm{C}$ with a mechanical strain range of $\pm 0.003 \mathrm{~m} / \mathrm{m}$ was used. In-phase hysteresis loops taken from three of the tests are shown in Fig. 16. Note the absence of abnormal distortions at reversal locations and the distinctive thermomechanical slope changes which occur, most notably in the compressive $800-1000^{\circ} \mathrm{C}$ deformation. These subtle variations are easily lost if well controlled conditions are not maintained. 
subtle variations are easily lost if well controlled conditions are not maintained.

Performing this series of definitive tests enabled the thermomechanical hardening mechanisms and behavior of Hastelloy $\mathrm{X}$ to be studied in detail, leading to the identification of behavior unique to thermomechanical loading conditions [13,14]. Most recently, these data were used to provide guidance for the development of thermoviscoplastic constitutive theories.

\section{Summary}

The following conclusions were drawn from this study of thermomechanical testing techniques and procedures.

1) The feasibility of generating reliable thermomechanical deformation data was demonstrated using state-of-the-art, computer controlled test equipment. Some improvements in temperature measurement, specimen heating, and specimen design were found to be necessary in achieving this goal.

2) Specimen barreling in out-of-phase tests conducted on Hastelloy $X$ was effectively eliminated by controlling axial thermal gradients within $\pm 2{ }^{\circ} \mathrm{C}$ over the gage section at the hot end of the cycle. The degree of specimen barreling in less closely controlled tests was shown to increase dramatically as the mechanical component of strain was increased.

3) A procedure was developed for thermal strain compensation which uses linear and piece-wise linear relationships between thermal strain and real-time specimen temperature. Straightforward experimental techniques were developed to check the effectiveness of the thermal strain compensation prior to testing.

4) A technique was developed to ensure proper phasing between temperature and the mechanical component of strain. Temperature is slaved to mechanical strain over the major part of the cycle and decoupled during reversals. Reasonably precise phasing is achieved during reversals by tailoring the temperature command waveform to the thermal characteristics of the test system.

5) The techniques and procedures developed in this study were used successfully to generate definitive thermomechanical deformation data for Hastelloy X.

\section{Acknowledgements}

The authors wish to acknowledge Chris Burke, Ralph Corner, and Ron Shinn for their technical support in the high temperature fatigue and structures laboratory at NASA Lewis Research Center. 


\section{References}

1. Hopkins, S.W.: Low-Cycle Thermal Mechanical Fatigue Testing. Thermal Fatigue of Materials and Components, ASTM STP-612, D.A. Spera and D.F. Mowbray, eds., American Society of Testing and Materials, Philadelphia, PA, 1976, pp. 157-169.

2. Jones, W.B.; Schmale, D.T.; and Bourcier, R.J.: A Test System for ComputerControlled Thermomechanical Fatigue Testing. Report SAND-88-2183C, Sandia National Laboratories, Albuquerque, NM, 1988.

3. Ellis, J.R.; and Robinson, R.N.: Some Advances in Experimentation Supporting Development of Viscoplastic Constitutive Models. NASA CR-174855, 1985.

4. Bakis, C.E.; Castelli, M.G.; and Ellis, J.R.: Thermomechanical Testing in Torsion: Test Control and Deformation Behavior. To be published in Multiaxial Fatigue Behavior, ASTM STP-1191, D.L. McDowell and J.R. Ellis, eds., American Society of Testing and Materials, Philadelphia, PA, 1993.

5. Carden, A.E.; and Slade, T.B.: High-Temperature Low-Cycle Fatigue Experiments on Hastelloy X. Fatigue at High Temperature, ASTM STP-459, American Society of Testing and Materials, Philadelphia, PA, 1969, pp. 111-129.

6. Coffin, L.F., Jr.: The Stability of Metals Under Cyclic Plastic Strain. J. Basic Eng., vol. 82D, Sept. 1960, pp. 671-682.

7. Li, P.; Marchand, N.J.; and Ilschner, B.: Inhomogeneous Cyclic Deformation Behavior of Polycrystalline Aluminum. Low-Cycle Fatigue and Elasto-Plastic Behaviour of Materials, K.-T. Rie, ed., Elsevier Applied Science, New York, 1988, pp. 55-64.

8. Conway, J.B.; Stentz, R.H.; and Berling, J.T.: High Temperature, Low-Cycle Fatigue of Copper-Base Allows in Argon; Part II-Zirconium-Copper at 482, 538 and 593 C. NASA CR-121260, 1973.

9. Sheffler, K.D.; and Doble, G.S.: Influence of Creep Damage on the Low-Cycle Thermal-Mechanical Fatigue Behavior of Two Tantalum Base Alloys. NASA CR-121001, 1972.

10. Avery, L.R.; Carayanis, G.S.; and Michky, G.L.: Thermal-Fatigue Tests of Restrained Combustor-Cooling Tubes. Exp. Mech., vol. 7, no. 6, June 1967, pp. 256-264.

11. Verrilli, M.J.; Kim, Y.S.; and Gabb, T.P.: High Temperature Fatigue Behavior of Tungsten Copper Composites. NASA TM-102404, 1989. 
12. Ellis, J.R.; and Bartolotta, P.A.: Adjustable Induction Heating Coil. NASA Tech. Brief, vol. 14, no. 11, Nov. 1990, p. 50.

13. Miner, R.V.; and Castelli, M.G.: Hardening Mechanisms in a Dynamic Strain Aging Alloy, Hastelloy X, During Isothermal and Thermomechanical Cyclic Deformation. Metall. Trans., vol 23A, Feb. 1992, pp. 551-562.

14. Castelli, M.G.; Miner, R.V.; and Robinson, D.N.: Thermomechanical Deformation Behavior of a Dynamic Strain Aging Alloy, Hastelloy X. To be published in Thermo-Mechanical Fatigue Behavior of Materials, ASTM STP-1186, H. Sehitoglu, ed., American Society of Testing and Materials, Philadelphia, PA, 1993. (Also, NASA TM-105316, 1992.)

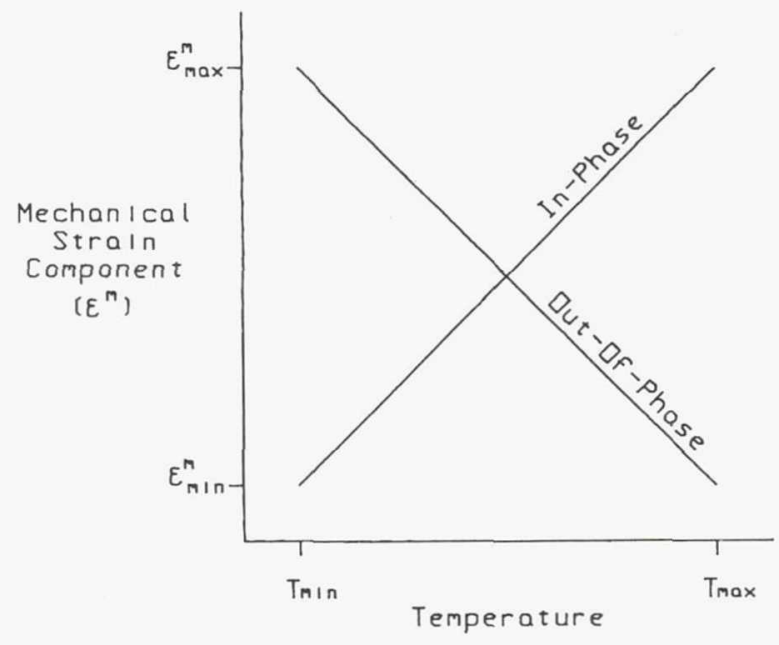

Note: Mechanical Strain $\left(\varepsilon^{n}\right)$ = Total Strain (e) - Thernal Strain $\left(\varepsilon^{\text {th }}\right)$

Figure 1.-Typical phasing relationships in strain controlled thermomechanical loading.

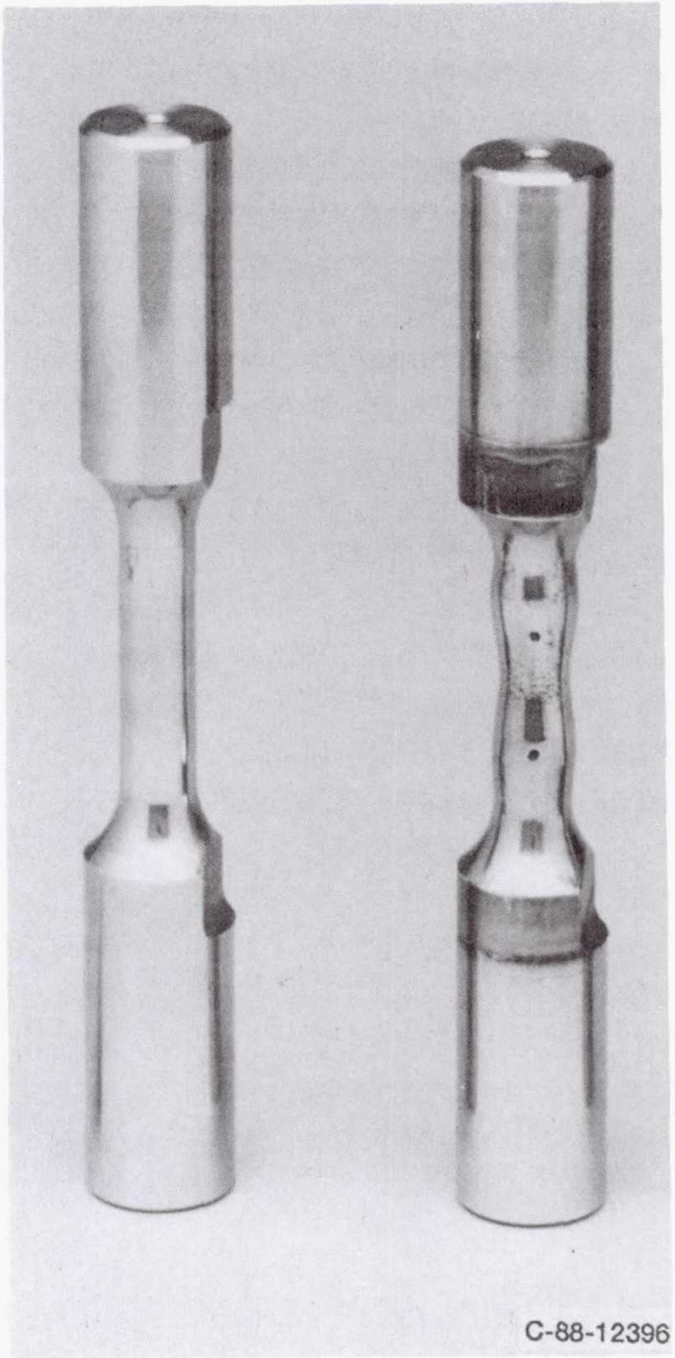

Figure 2.-Specimen before and after cyclic barreling. 


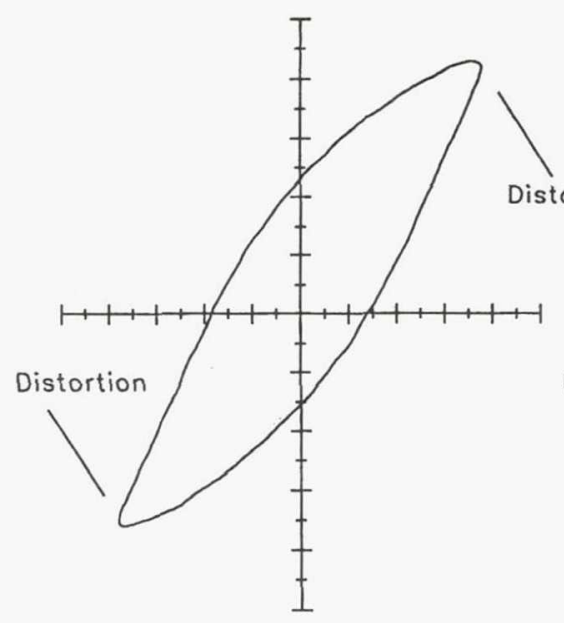

(a) Stress versus total strain.

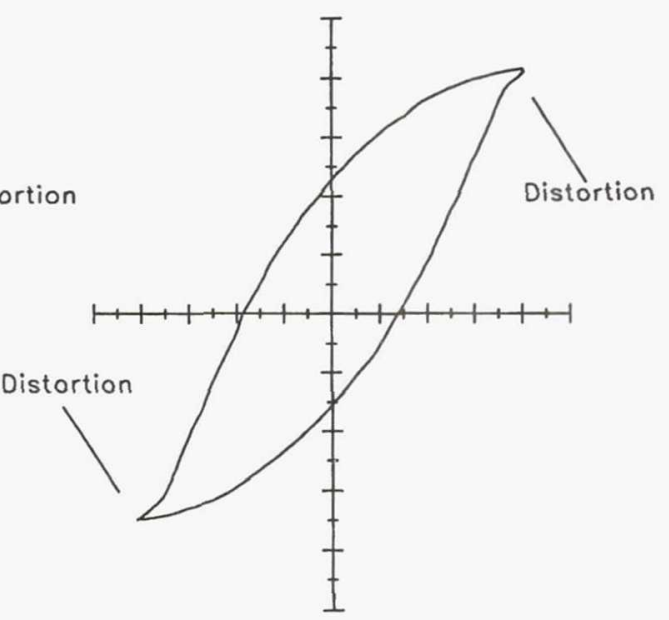

(b) Stress versus mechanical strain.

Figure 3.-Typical distortions found in hysteresis loops where phasing problems exist.

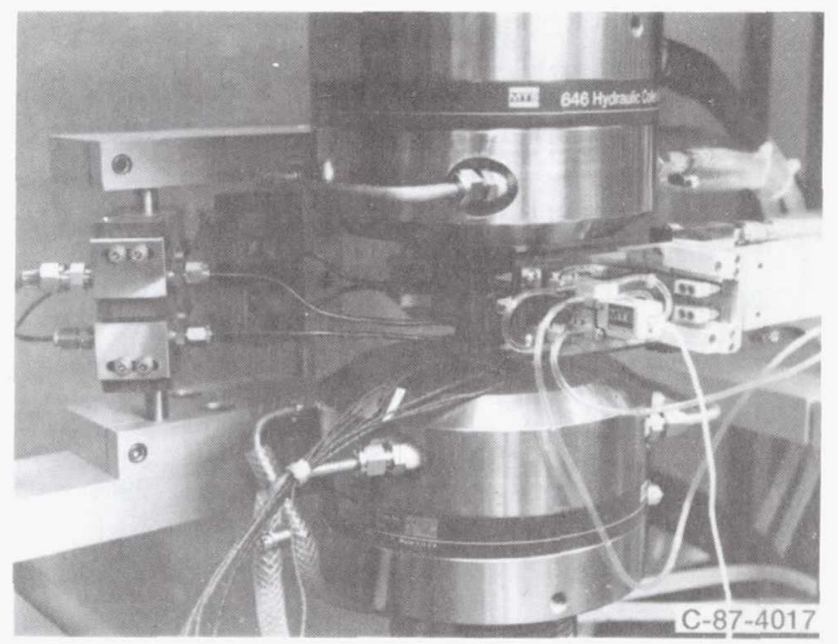

Figure 4.-Experimental setup used for thermomechanical testing.

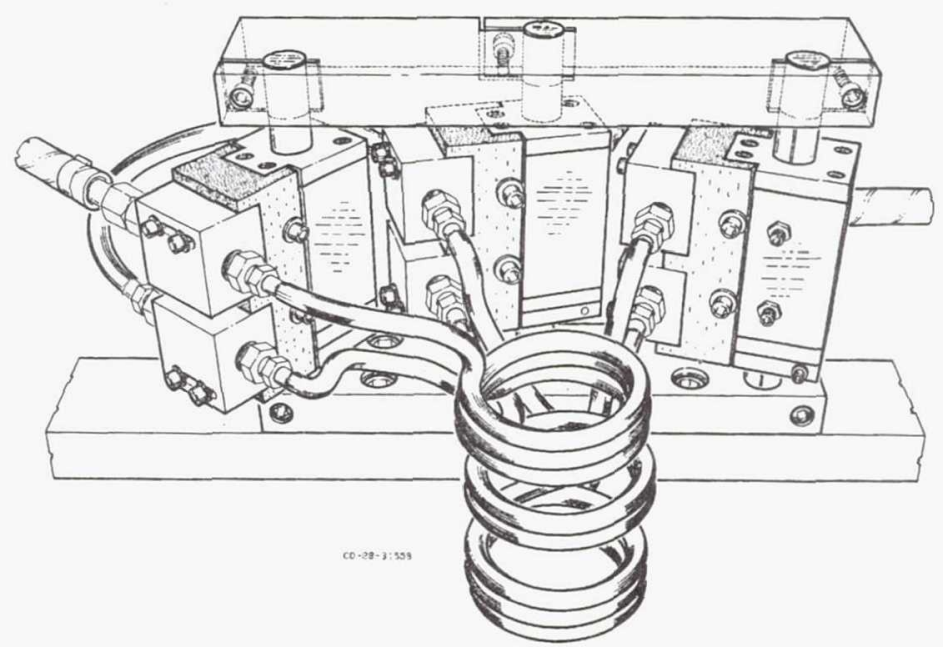

Figure 5.-Adjustable work coil fixture for direct induction heating. 


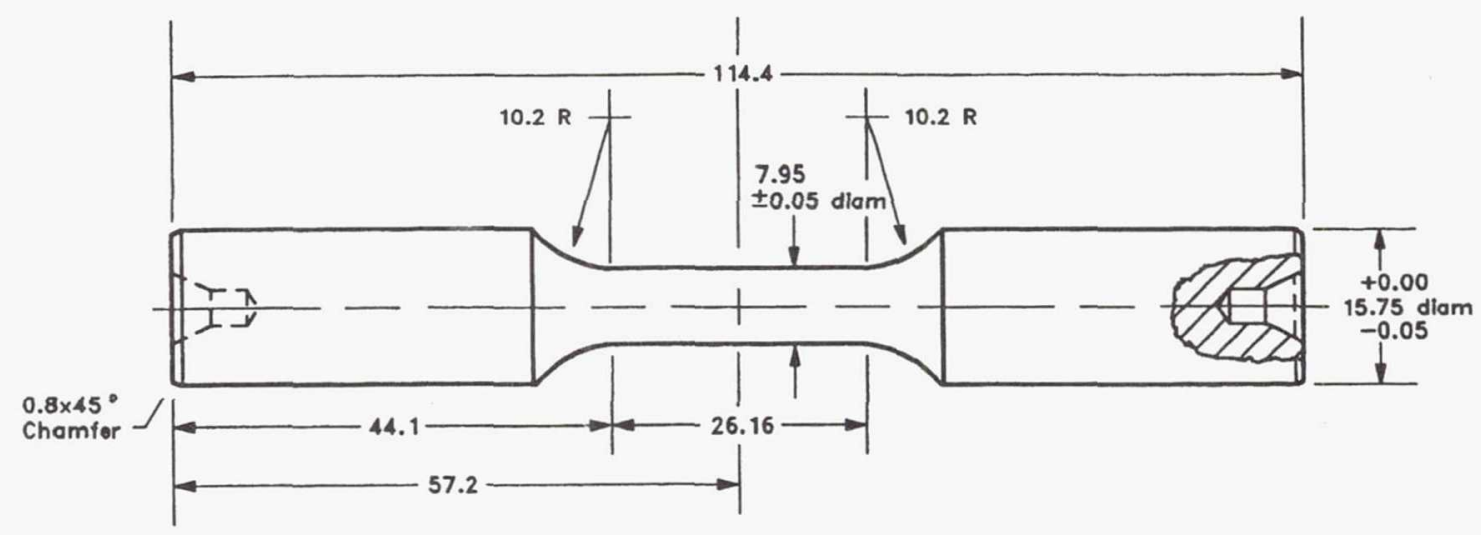

(a) Solid.

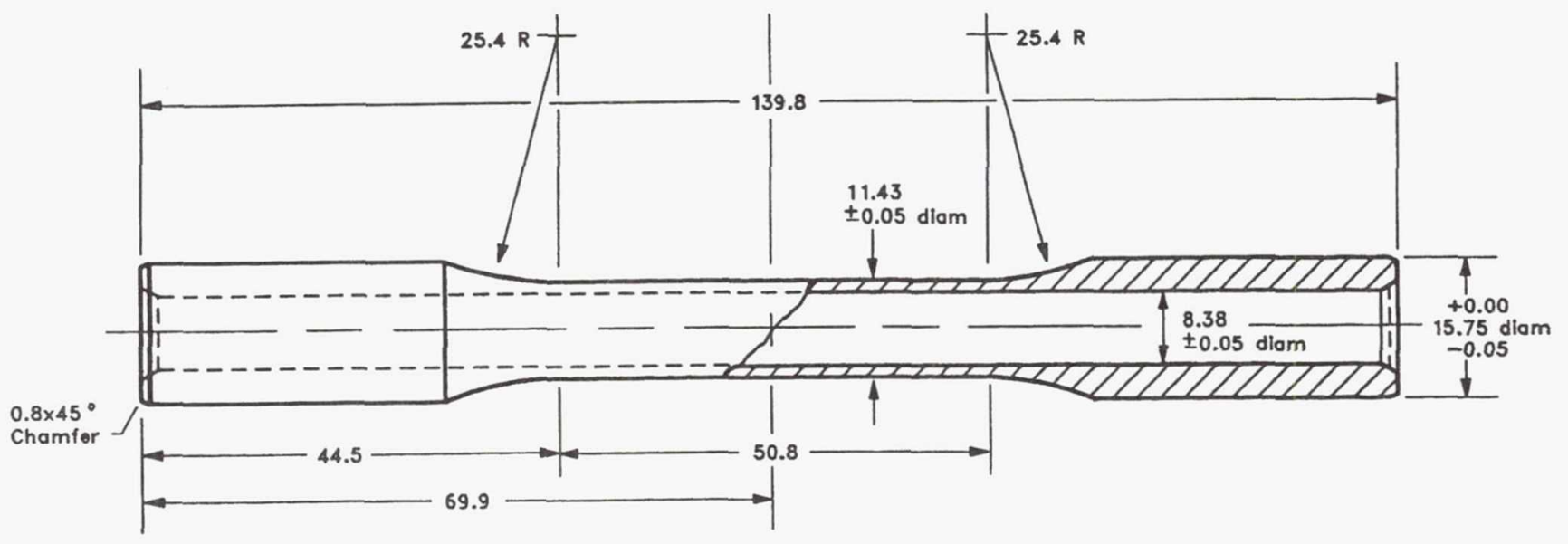

(b) Improved tubular construction for thermomechanical testing.

Figure 6. Specimen designs. Dimensions given in millimeters.

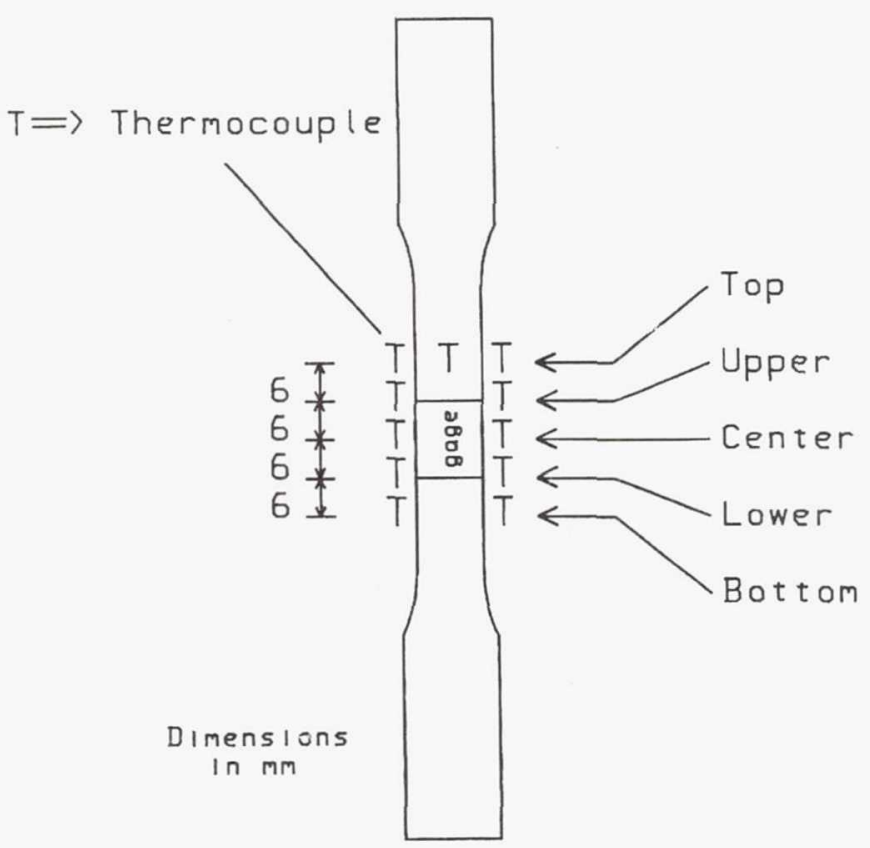

Figure 7.-Thermocouple configuration. 


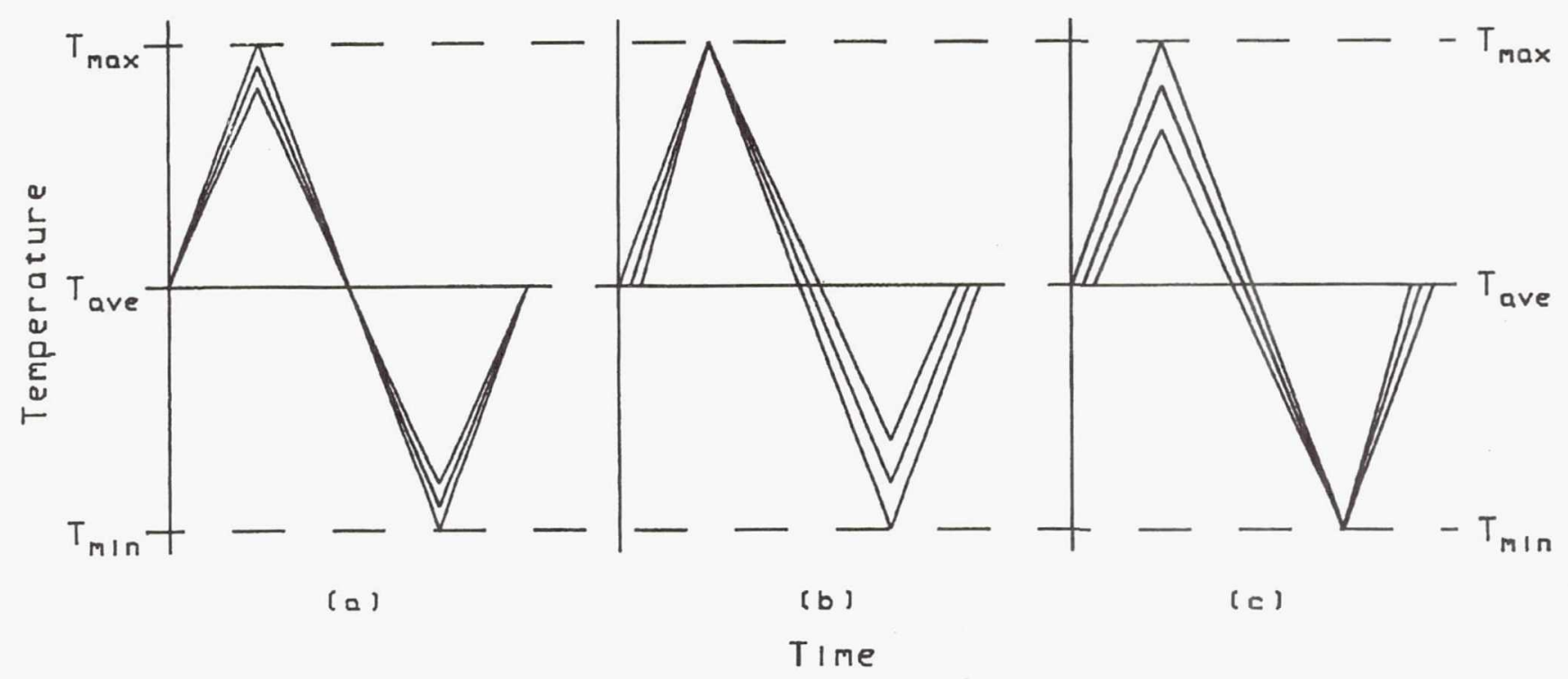

Note: The curves represent temperature historles measured at upper. central. and
lower locations within the gage sectlon. Thus, at any given time. curve
separations are Indicative of thermal gradients over the specimen gage sectlon.

Figure 8.-Alignment temperatures for dynamic thermal gradients; (a) average; (b) maximum; (c) minimum.

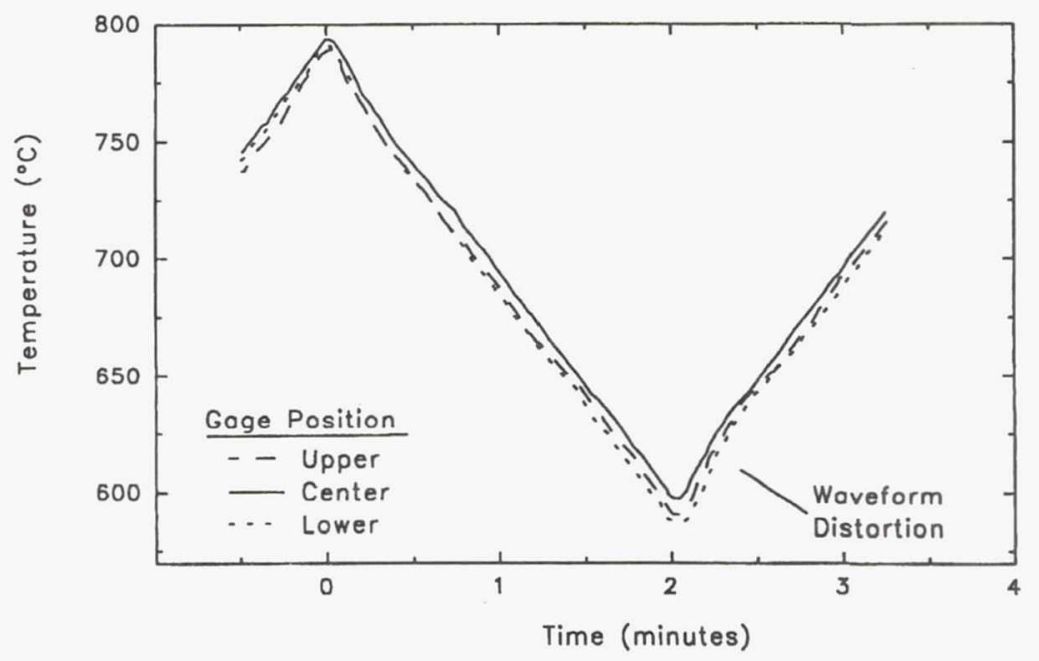

Figure 9.-Thermal profile with center thermocouple controlling. 


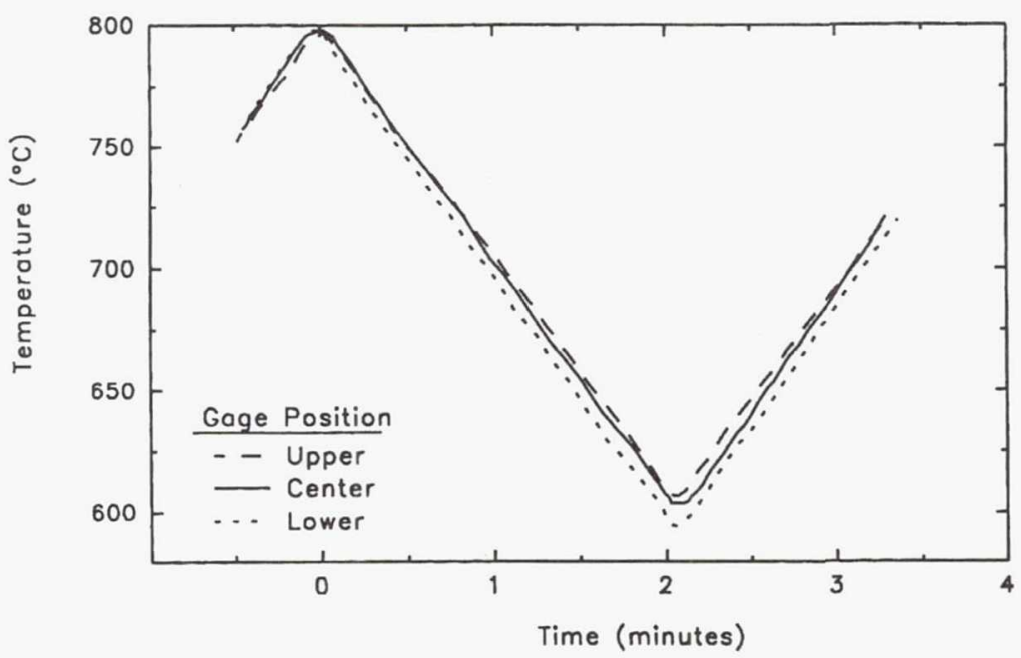

Figure 10.-Thermal profile with top thermocouple controlling.

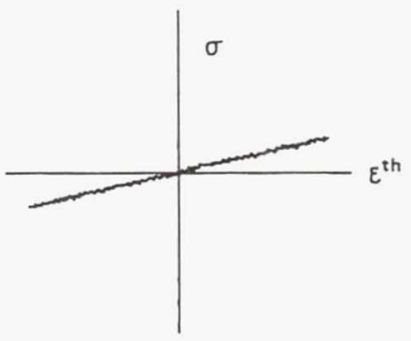

(a)

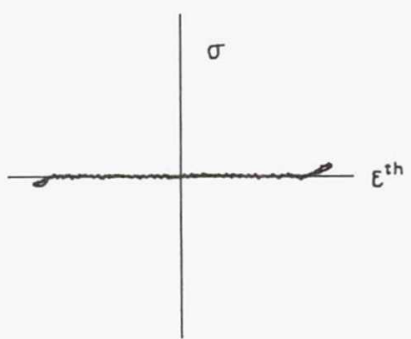

(c)

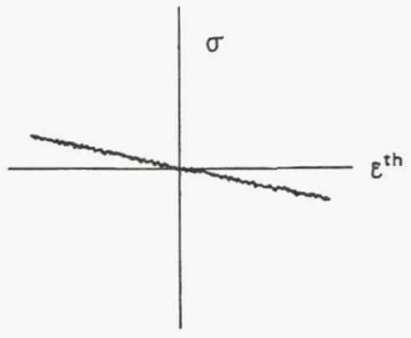

(b)

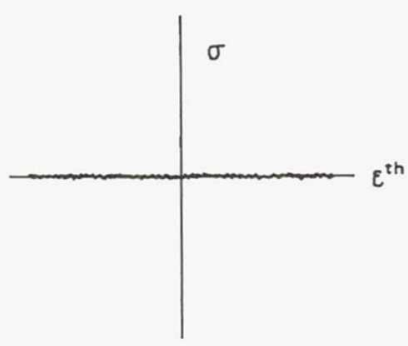

(d)

Figure 11.-Verification of the effective coefficient of thermal expansion $\left(\alpha^{*}\right)$ in the thermal strain compensation equation, $\epsilon^{\text {th }}=\alpha^{*} T+C\left(\alpha_{0}=\right.$ optimal value for $\left.\alpha^{\star}\right)$; (a) $\alpha^{\star}>\alpha_{0}$; (b) $\alpha^{\star}<\alpha_{0}$; (c) temperature rate is too fast; and (d) $\alpha^{\star}=\alpha_{0}$. 


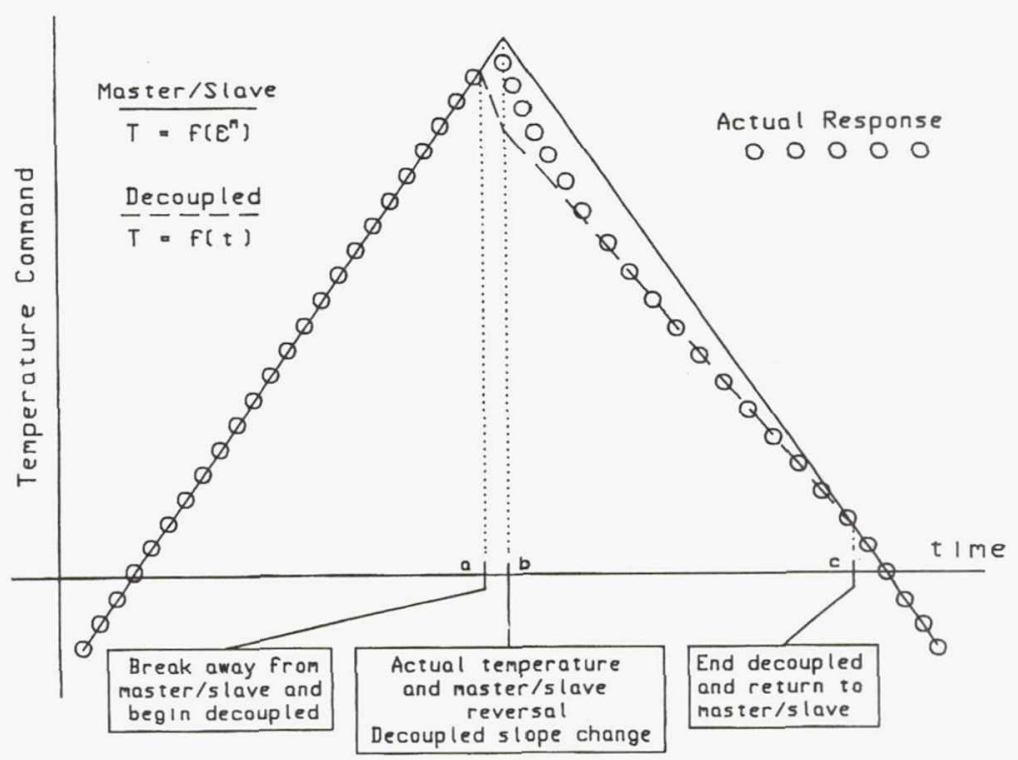

Figure 12.-Schematic of temperature command sequence.

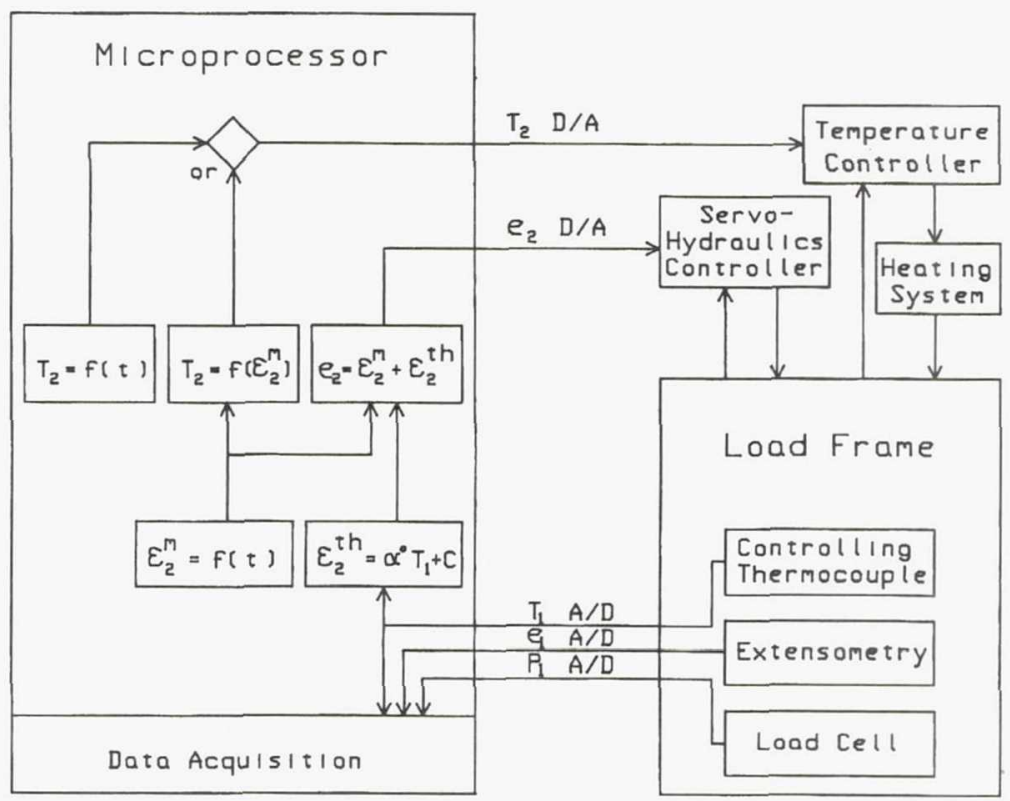

Figure 13.-Schematic flow diagram depicting the command and execution sequencing for strain controlled thermomechanical testing. 


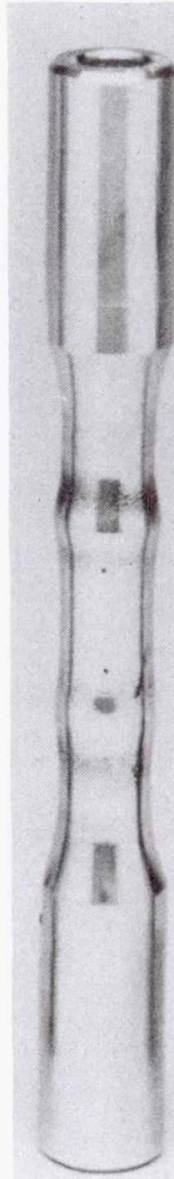

(a)

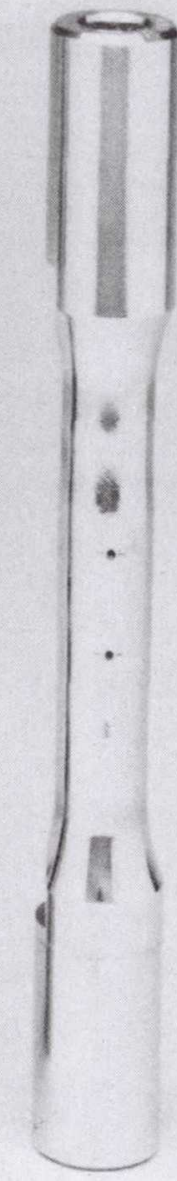

(b)

C-88-12398

Figure 14.-Specimen barreling; (a) after 500 cycles, before improved techniques; (b) after 1100 cycles with improved control techniques. 


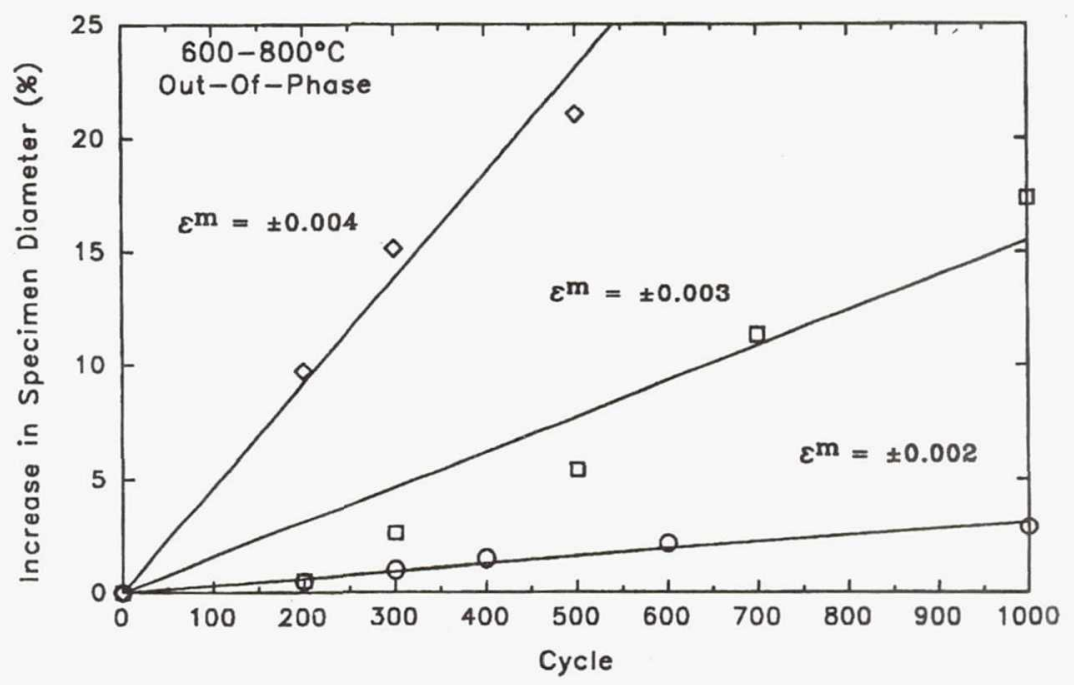

Figure 15.-Effect of mechanical strain range on specimen barreling for 600 $800{ }^{\circ} \mathrm{C}$ out-of-phase.

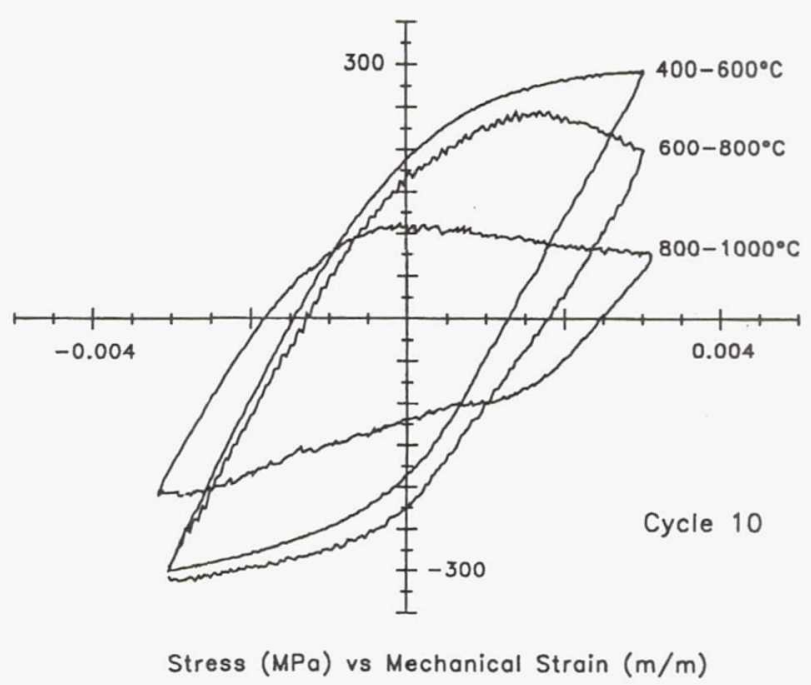

Figure 16.- In-phase hysteresis loops for Hastelloy $X$ exhibiting minimal distortions. 
Public reporting burden for this collection of information is estimated to average 1 hour per response, including the time for reviewing instructions, searching existing data sources, gathering and maintaining the data needed, and completing and reviewing the collection of information. Send comments regarding this burden estimate or any other aspect of this collection of information, including suggestions for reducing this burden, to Washington Headquarters Services, Directorate for information Operations and Reports, 1215 Jefferson Davis Highway, Suite 1204, Arlington, VA 22202-4302, and to the Office of Management and Budget, Paperwork Reduction Project (0704-0188), Washington, DC 20503.

\begin{tabular}{|l|l|l|}
\hline 1. AGENCY USE ONLY (Leave blank) & $\begin{array}{c}\text { 2. REPORT DATE } \\
\text { November } 1992\end{array}$ & $\begin{array}{r}\text { 3. REPORT TYPE AND DATES COVERED } \\
\text { Technical Memorandum }\end{array}$
\end{tabular}

4. TITLE AND SUBTITLE

5. FUNDING NUMBERS

Improved Techniques for Thermomechanical Testing in Support of

Deformation Modeling

6. AUTHOR(S)

WU-505-63-40

Michael G. Castelli and John R. Ellis

\section{PERFORMING ORGANIZATION NAME(S) AND ADDRESS(ES)}

Sverdrup Technology, Inc.

Lewis Research Center Group

2001 Aerospace Parkway

Brook Park, Ohio 44142
8. PERFORMING ORGANIZATION REPORT NUMBER

E-7568
9. SPONSORING/MONITORING AGENCY NAMES(S) AND ADDRESS(ES)

10. SPONSORING/MONITORING AGENCY REPORT NUMBER

National Aeronautics and Space Administration

Lewis Research Center

Cleveland, Ohio 44135-3191
NASA TM-105944

\section{SUPPLEMENTARY NOTES}

Michael G. Castelli, Sverdrup Technology, Inc., Lewis Research Center Group, 2001 Aerospace Parkway, Brook Park, Ohio 44142 and John R. Ellis, NASA Lewis Research Center, Cleveland, Ohio. Responsible person, Michael G. Castelli, (216) 433-8464.

12a. DISTRIBUTION/AVAILABILITY STATEMENT

12b. DISTRIBUTION CODE

Unclassified - Unlimited

Subject Category 39

\section{ABSTRACT (Maximum 200 words)}

The feasibility of generating precise thermomechanical deformation data to support constitutive model development was investigated. Here, the requirement is for experimental data that is free from anomalies caused by less than ideal equipment and procedures. A series of exploratory tests conducted on Hastelloy X showed that generally accepted techniques for strain controlled tests were lacking in at least three areas. Specifically, problems were encountered with specimen stability, thermal strain compensation and temperature/mechanical strain phasing. The present study was undertaken to identify the source of these difficulties and to develop improved thermomechanical testing techniques to correct them. These goals were achieved by developing improved procedures for measuring and controlling thermal gradients and by designing a specimen specifically for thermomechanical testing. In addition, innovative control strategies were developed to correctly proportion and phase the thermal and mechanical components of strain. Subsequently, the improved techniques were used to generate deformation data for Hastelloy X over the temperature range, 200 to $1000{ }^{\circ} \mathrm{C}$.

\section{SUBJECT TERMS}

Thermomechanical testing; Testing techniques; Specimen instability; Constitutive modeling; barreling

\begin{tabular}{l|c} 
17. SECURITY CLASSIFICATION & $\begin{array}{c}\text { 18. SECURITY CLASSIFICATION } \\
\text { OF REPORT }\end{array}$ \\
OF THIS PAGE \\
Unclassified
\end{tabular}

NSN 7540-01-280-5500

19. SECURITY CLASSIFICATION
OF ABSTRACT
Unclassified
SECURITY CLASSIFICATION Unclassified


National Aeronautics and

Space Administration

Lewis Research Center

Cleveland, Ohio 44135

Official Business

Penalty for Private Use $\$ 300$
FOURTH CLASS MAIL

ADDRESS CORRECTION REQUESTED

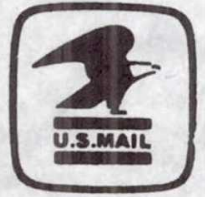

Postage and Fees Paid Natıonal Aeronautics and

Space Administralion

NASA 451 